\title{
The Mechanical Behavior of Bone Cement in THR in the Presence of Cavities
}

\author{
A. Benouis \\ Mechanical Engineering Department \\ Djillali Liabes University of Sidi \\ Bel-Abbes, Algeria \\ alymoh1980@yahoo.fr
}

\author{
B. Serier \\ Mechanical Engineering Department \\ Djillali Liabes University of Sidi \\ Bel-Abbes, Algeria \\ serielem@yahoo.fr
}

\author{
B. Bachir Bouiadjra \\ Mechanical Engineering Department \\ Djillali Liabes University of Sidi \\ Bel-Abbes, Algeria \\ bachirbou@yahoo.fr
}

\begin{abstract}
In this work we analyze three-dimensionally using the finite element method, the level and the Von Mises stress equivalent distribution induced around a cavity and between two cavities located in the proximal and distal bone cement polymethylmethacrylate (PMMA). The effects of the position around two main axes (vertical and horizontal) of the cavity with respect to these axes, of the cavity - cavity interdistance and of the type of loading (static) on the mechanical behavior of cement orthopedic are highlighted. We show that the breaking strain of the cement is largely taken when the cement in its proximallateral part contains cavities very close adjacent to each other. This work highlights not only the effect of the density of cavities, in our case simulated by cavity-cavity interdistance, but also the nature of the activity of the patient (patient standing corresponding to static efforts) on the mechanical behavior of cement.
\end{abstract}

Keywords- bone cement; constraint; cavity; implant; interaction; statics

\section{INTRODUCTION}

Cements based on acrylic resin bone currently used in orthopedic surgery are PMMA (polymethylmethacrylate) selfhardening rapid polymerization type. They are used for sealing prostheses in living bone during partial or total hip replacement, knee and other joints. Several studies on the analysis of the stress distribution in the orthopedic cement have been conducted. Benbarek et al [1] have numerically analyzed, using the finite elements method, the effect of the orientation of the axis of the implant in relation to that of the cup, on the level and distribution of stresses in bone cement containing a microcavity and hence the stress intensity factor at the crack tip heads from said cavity. In another study, Bachir Bouiadjra et al [2] have studied the behavior of cement out of the acetabulum by analyzing the intensity factor. They show that the fracture mode depends on the position of the crack. Benbarek et al [1] showed that the stress intensity factors in mode I and mode II depend not only on the direction of the crack initiated in the cement but also on the axis of the implant in relation to the cup. Serier et al [3] have analyzed the effect of the position of the initial crack according to the position of the axis of the implant in relation to that of the cup, on the stress intensity factor. Bouziane et al [4] showed three-dimensionally, using the finite element method, that the presence of cavities or bone inclusion in the cement, is a source of stress concentration. This study is in this context and analyzes three-dimensionally, using the finite element method, the amplitude of the induced stresses in the bone cement around a cavity, and the effects of the interaction of the implant-cement interface with another cavity on the intensity and the distribution of stresses in the material. This study was conducted in order to understand and explain the interconnecting cavities via cracks phenomena observed experimentally [5]. To do this, the effect of two patient activities on the mechanical behavior of cement was analyzed: standing position simulated by static forces and normal walking simulated by dynamic forces.

A number of studies have investigated the performance of cemented prosthesis in terms of prosthesis survival [6-10]. It should be noted that, in general, cemented THR is relatively less expensive than uncemented THR [11]. Daan Waanders et al [11] studied the micromechanical behavior of cement near the cement-bone interface on PTH damage. Zouambi et al [13] have studied the behavior of bone cement into the acétabulum, and the effect of the presence of defects and their interactions; they show that an increase in the defect density results in significant stress intensity.

\section{PRESENTATION OF MODEL}

This analysis uses the modeling of femur THR (total hip replacement) in three dimensions. This modeling was done using the ABAQUS 6.11.1 finite element software [14]. The complex geometry of a femoral bone implant, related with a cortical bone and cancellous bone through the bone cement, and is shown in Figure 1. The cavities are placed in the analyzed region more solicited of the cement. That is to say, on the part of the cement, that it is under heavy intensity stress. It is in this part where the risk of fracture of the cement, thereby loosening, is the most probable. The mechanical properties of the components of the prosthesis and its structure consists of the elements shown in Table 1.

\section{BOUNDARY CONDITIONS AND LOADING}

There are currently several models sold in total hip replacement, among which are: CMK, BM, and FRAM.A for the choice of model used in the simulation, we chose the CMK.3 (third generation prosthesis Carnley of KERBOOLL) due to its availability in the domestic market. The chosen 
model is characterized by the specific dimensions and mechanical properties of its components which are listed in Table I: the femoral implant, cement and bone. For static analysis, a dependent of a person of $80 \mathrm{~kg}$ applied to the femoral head [15] as shown in Figure 1 [16]. A load abductor muscle is applied in the anterior proximal $\left(\mathrm{F}_{\text {abductor }}\right)$, and a Vastus lateralis load is applied to the proximal side, as represented in Table II, and at fitting in imposed on the distal femur.

We analyzed the mechanical behavior of cement during the process of normal walking of the patient; the decomposition cycle is illustrated in Figure 2. This patient activity is simulated by dynamic forces. The mesh of the cement around the cavity at the interface with cavity and cement and interdistance between two cavities are shown in Figure 3.

\section{RESULTS}

A. Stress distribution in the cement sound (cavity free)

For a better illustration of the effect of the presence of a cavity in the bone cement on the intensity and distribution of the Von Mises stress induced in objects subjected to mechanical stress, Figure 4 illustrates the variation of this constraint in the proximal, median and distal parts of the heart cement sound (cavity free). Constraints induced by static were analyzed around the cement noted in zones A, B and C (Anterior, Lateral and Posterior) in the proximal, medial and distal parts. This figure clearly shows that the highest stresses are induced in the proximal-lateral cement. The intensity of these stresses is significantly higher than that induced in the medial side. This high level of stress is due to the load applied to the implant as well as to the abduction charges. In this area of high stress localized cavities will be considered in order to analyze their effect on the mechanical behavior. Constraints caused in heel strike are more intense than those resulting from static loads.

TABLE I. MATERIAL PROPERTIES OF FEMUR THR [12]

\begin{tabular}{|c|c|c|c|}
\hline Part of Model & Material & Elastic Modulus (Gpa) & Poisson's Ratio \\
\hline Stem & CoCr-alloy/stainless steel & 210 & 0.3 \\
\hline Cement & Poltymethylmethacrylate & 2.4 & 0.3 \\
\hline Cancellous bone & Polyurethane foam & 0.4 & 0.3 \\
\hline Cortical bone & Glass-fiber-reinforced epoxy & $\mathrm{E}_{\mathrm{x}}, \mathrm{E}_{\mathrm{y}}=7.0, \mathrm{E}_{\mathrm{z}}=11.5$ & $\mathrm{v}_{\mathrm{xy}}, v_{\mathrm{zy}}, v_{\mathrm{zx}}=0.4$ \\
\hline
\end{tabular}

TABLE II. MAXIMUM LOADING CONFIGURATIONS OF THE MAJOR MUSCLES [17]

\begin{tabular}{|c|c|c|c|c|}
\hline \multicolumn{5}{|c|}{ Normal walking } \\
\hline Force (N) & $\mathbf{X}$ & $\mathbf{Y}$ & $\mathbf{Z}$ & $\mathbf{F}$ \\
\hline Joint contact force & -433.8 & -263.8 & -1841.3 & $\mathrm{~F}_{\text {static }}$ \\
\hline Abductor muscle & 465.9 & 34.5 & 695.0 & $\mathrm{~F}_{1}$ \\
\hline Vastus Lateralis muscle & -7.2 & 148.6 & -746.3 & $\mathrm{~F}_{2}$ \\
\hline
\end{tabular}

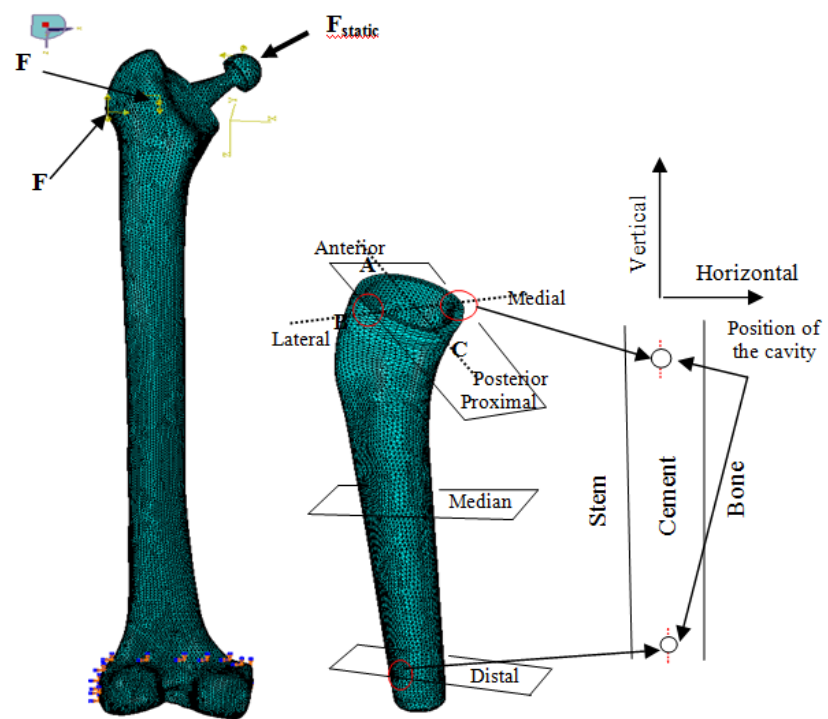

Fig. 1. Model, mesh, boundary conditions and static loads applied to the structure analyzed.

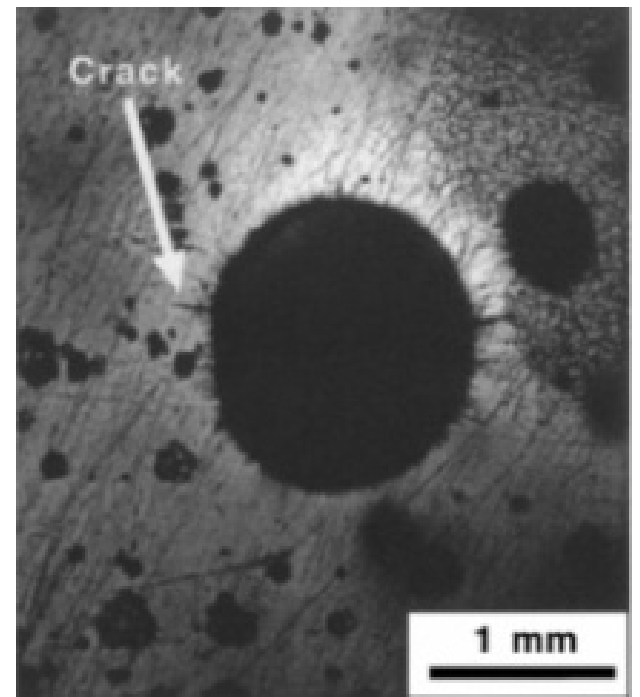

Fig. 2. Cracks in acrylic bone cement observed under transmitted light 


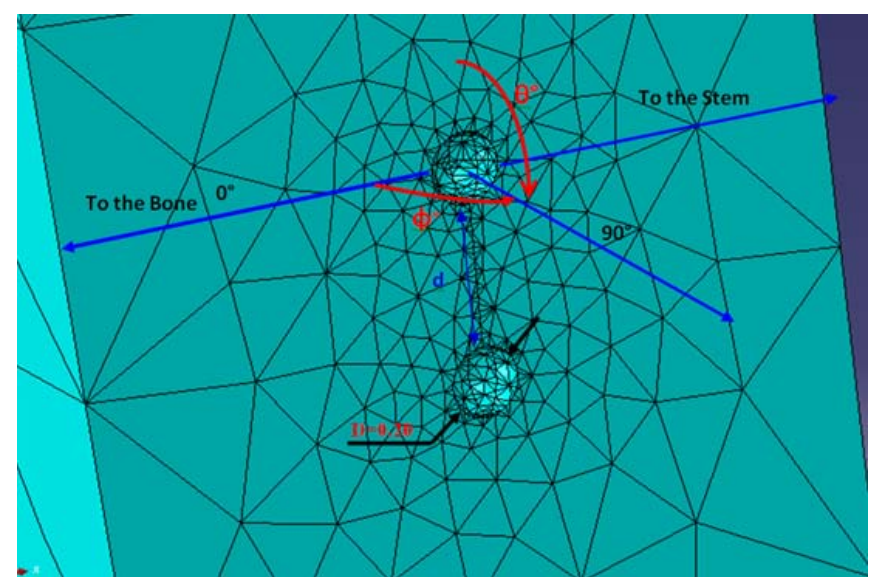

Fig. 3. Mesh cement around the cavity

\section{B. Effect of a cavity located in the heart of cement}

The cavity is placed in the heart of the bone cement in the proximal and distal parts away from the cement-stem interface. Constraints have been analyzed in the cement around the cavity in a $\phi$ relative to the axes of the cavity angle. Recall that angle $\phi=0^{\circ}$ corresponds to the horizontal axis in the direction toward the bone implant, and $\phi=90^{\circ}$ to the vertical axis and the angles of $45^{\circ}$ and $135^{\circ}$ are located at $45^{\circ}$ to either of these other two axes. The effect of the cavity on the level and distribution constraints of equivalent Von Mises on the proximal lateral and medial parts are illustrated in Figure 5. According to this latter approach, cement usage is lower as given in Figure 5. Figure $5 \mathrm{~b}$ shows that on its lateral region, the cement is high solicited and that these constraints are lower than those induced by a cavity located near the interface level as seen in Figure 4. The most intense stresses are generated around the vertical axis $(\phi=$ $90^{\circ}$ ). Around the other directions constraints are relatively low. Compared to the lateral region, the most important constraints induced on the medial region are related to the horizontal axis $\left(\phi=0^{\circ}\right)$, followed by $90^{\circ}, 135^{\circ}$ and $45^{\circ}$. As can be seen from Figure 6 , the distal part is subject to low intensity stress. This is along the vertical axis were the stresses are highly localized.
Our results show that the stresses induced in the lateral proximal part in the cement are comparable to the breaking yield stress of the cement. They may pose a risk of rupture to the cement, thus of loosing the total hip replacement.

\section{Effect of cavity-cavity interaction}

The presence of cavities can weaken the cement notch effect and interaction, thus it determines the sustainability of total hip replacement. The objective of this part of the study was the in three dimension analysis using the finite element method. Figure 7 represents the effect of cavity-cavity interaction on the level and the Von Mises stress distribution induced by static loading in the bone cement between the two defects. This figure shows that most important constraints are located in the cement between the cavities.

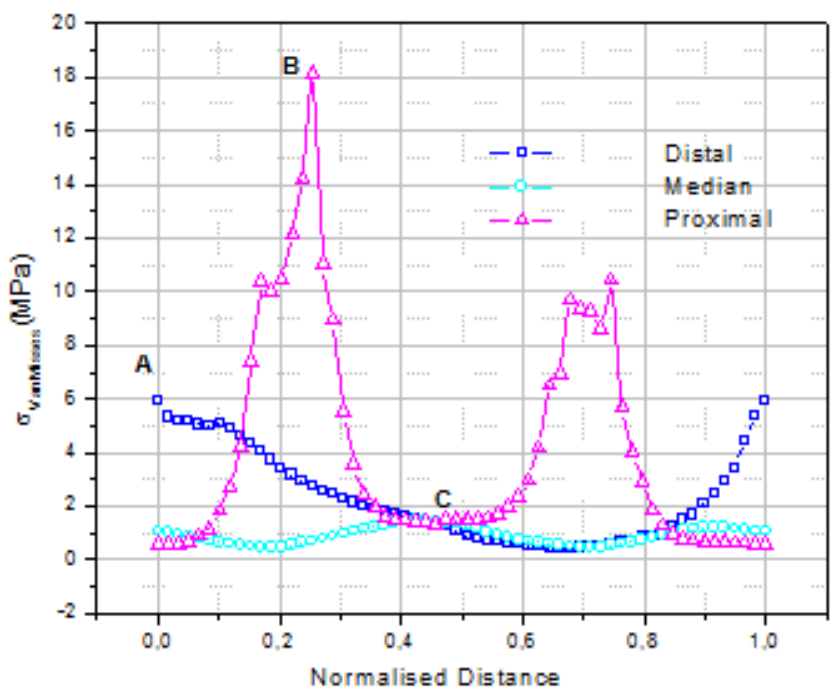

Fig. 4. Von Mises stresses Equivalent distribution on the bone cement around the perimeter $\mathrm{ABC}$.

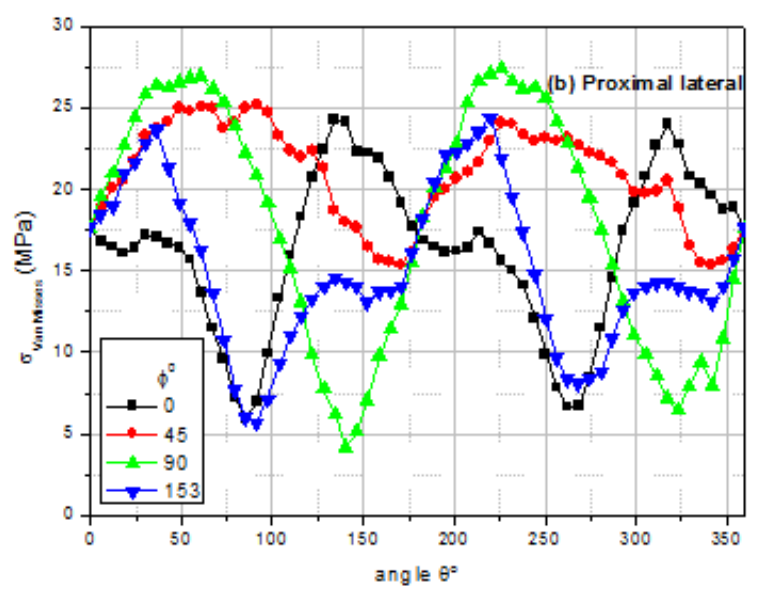

Fig. 5. Von Mises stress distribution in the proximal lateral and medial parts of the cement around the cavity (a), (b). 


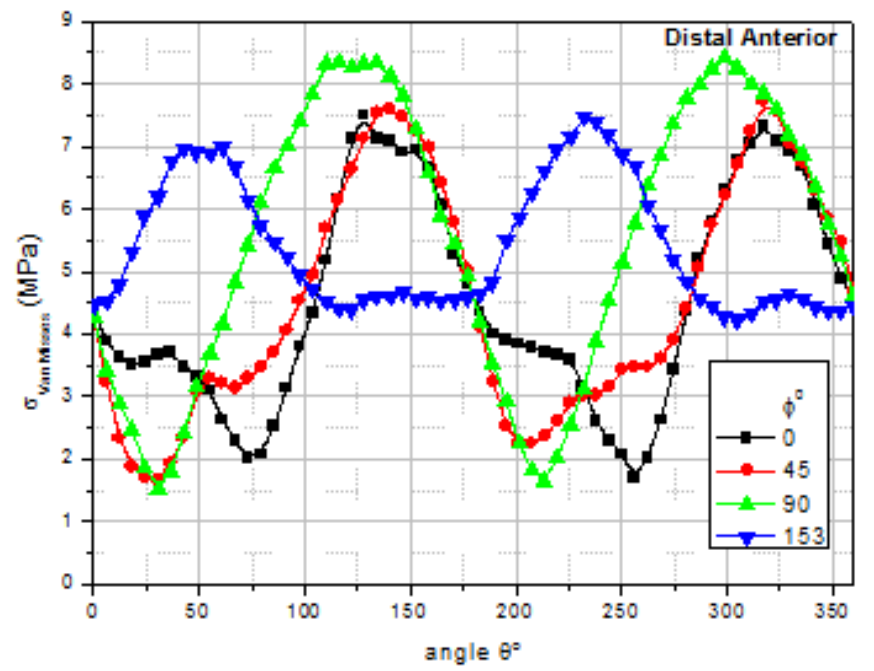

Fig. 6. Von Mises stress distribution in the distal part of the cement around the cavity.
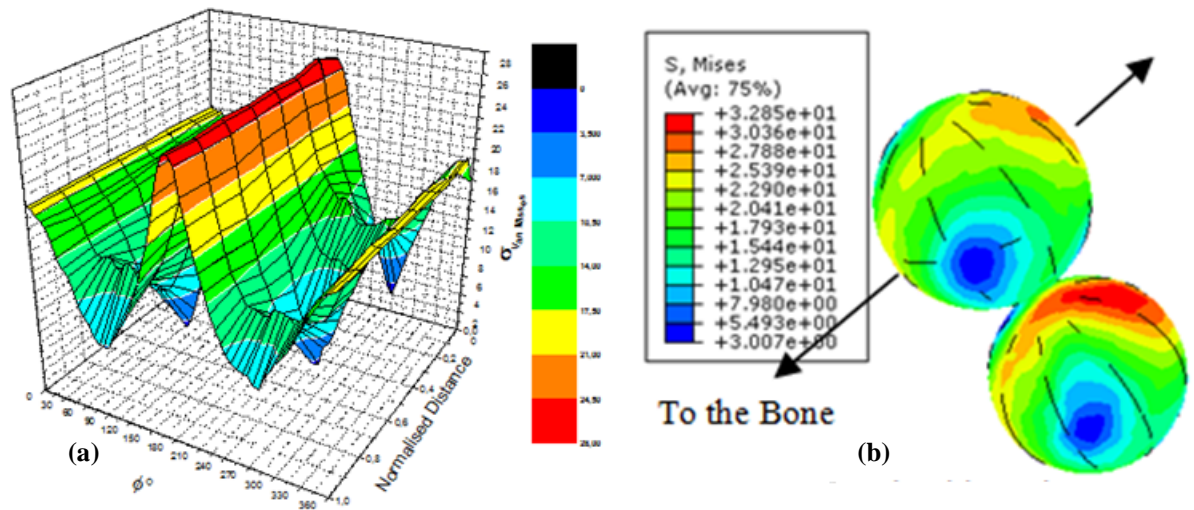

To the Stem

Fig. 7. Level and the equivalent stress distribution in the cement between two cavities at a distance $d=0.02 \mathrm{~mm}$ (a) The three-dimensional distribution of the Von Mises stress in the proximal lateral part cement around a cavity in another $0.20 \mathrm{~mm}$ (b) Procimal latera.

Figure 8 represents the change in the induced stress in the cement between the two cavities in relation to the distance between them. The level of stress increases significantly when these defects are located in vicinity to each other. In this case, the stresses generated exceed the breaking yield stress threshold of the cement, and tend to compress. Compared to the proximal part and no matter what the nature of the load, the distal part is subjected to stresses of low level, as shown in Figure 9a. A migration of a cavity leads to increased levels as shown in Figure 9b. The results obtained show that the Von Mises stresses induced between cavities in the bone cement in the proximal lateral part exceeds the breaking yield stress. This can lead to the initiation and propagation of cracks emanating from cavities and thus the interconnection of these volume defects. This seems to explain the experimental observation of this phenomenon [18]. This work highlights not only the effect of the density of the cavities, in our case simulated by cavity cavity interdistance, but also the effect of a patient's activity.

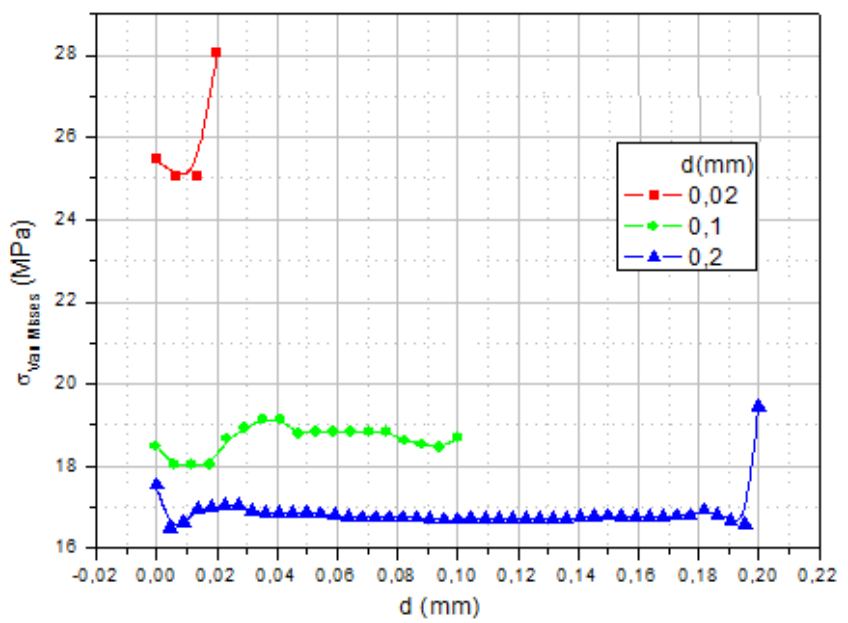

Fig. 8. The Von Mises stress induced in the cement between the two cavities according to the distance. 


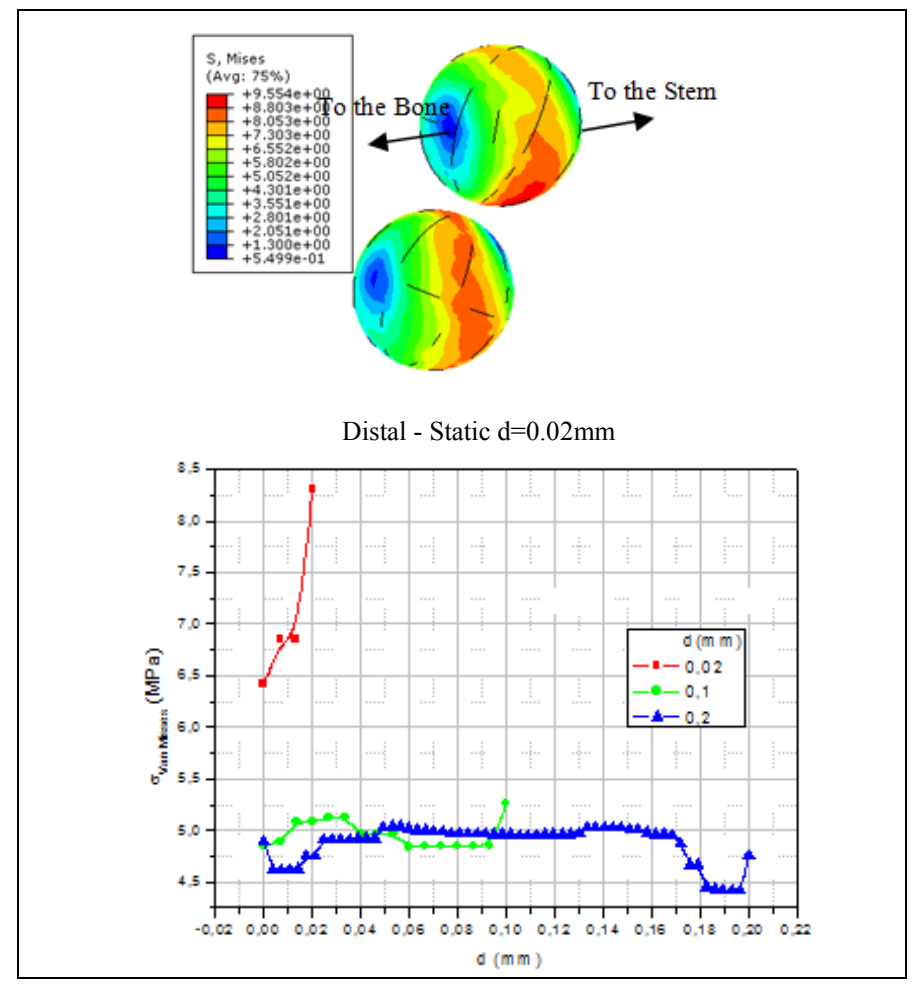

Fig. 9. The Von Mises stress induced in the cement between the two cavities according to the distance.

\section{DISCUSSION}

Porosity in the orthopedic cement plays a determining role for the diffusion of antibiotics; it constitutes a way of matter transfer. The results obtained in this work show that its presence in orthopedic cement is a source of stress concentration per notch effect. This effect is all the more important as the cavity is localized in the vicinity close to the interface with the implant. This cavity-interface interaction weakens the cement in traction. The interaction of the stress fields between these two defects is equivalent to the breaking stress. Such a position of the cavity presents a great risk of unsealing of the total prosthesis in the hip. This behavior is strongly accentuated by the localization of two cavity very close one to the other. Indeed the level of the constraints induced in the cement between these two defects, reaches that of its breaking stress in compression.

\section{CONCLUSION}

The results obtained in this work show that:

- The highest Von Mises stresses induced in empty cement of the cavities are located on the proximallateral part.

- Compared to the proximal part, the distal region of the cement is subjected to low amplitude constraints.

- The presence of cavity in the bone cement is the source of an additional constraint due to the notch effect. Its location at the heart of this binder creates an intense stress. This is according to the horizontal and vertical axes that the level of these constraints peaked (that is at the maximum level). This maximum exceeds the critical level of breaking stress of the cement.

- Compared to a cavity, the existence of a second adjacent cavity causes stronger Von Mises constraints in the bone cement. The intensity of these constraints depends of the position of the second cavity in relation to the first.

\section{REFERENCES}

[1] S. Benbarek, B. Bachir Bouiadjra, T. Achour, M. Belhouari, B. Serier, "Finite element analysis of the behaviour of crack emanating from microvoid in cement of reconstructed acetabulum", Materials Science and Engineering: A, Vol. 457, No. 1-2, pp. 385-391, 2007

[2] B. Bachir Bouiadjra, A. Belarbi, S. Benbarek, T. Achour, B. Serier, "FE analysis of the behaviour of microcracks in the cement mantle of reconstructed acetabulum in the total hip prosthesis, Computational Materials Science, Vol. 40, No. 4, pp. 485-491, 2007

[3] B. Serier, B. Bachir Bouiadjra, S. Benbarek, T. Achour, "Analysis of the effect of the forces during gait on the fracture behaviour in cement of reconstructed acetabulum", Computational Materials Science, Vol. 46, No. 2, pp. 267-274, 2009

[4] M. M. Bouziane, B. Bachir Bouiadjra, S. Benbarek, M. S. H. Tabeti, T. Achour, "Finite element analysis of the behaviour of microvoids in the cement mantle of cemented hip stem: static and dynamic analysis", Materials and Design, Vol. 31, No. 1, pp. 545-550, 2010

[5] P. Pernod, P. Hernigou, "Aspect morphologique de la porosité du ciment", Actualités en biomatériaux, Vol. 3, pp. 235-240, 1996

[6] R. M. Kay, F. J. Dorey, K. Johnston-Jones, A. Cracchiolo III, H. C. Amstutz, G. A. M. Finerman, "Long-term durability of cemented primary total hip arthroplasty", The Journal of Arthroplasty, Vol. 10, No. 1, pp. S29-S38, 1995

[7] R. P. Katz, J. J. Callaghan, P. M. Sullivan, R. C. Johnston, "Long-term results of revision total hip arthroplasty with improved cementing technique", Journal of Bone and Joint Surgery (British Volume), Vol. 79, No. 2, pp. 322-3266, 1997

[8] R. B. Bourne, C. H. Rorabeck, M. E. Ghazal, M. H. Lee, "Pain in the thigh following total hip replacement with a porous-coated anatomic prosthesis for osteoarthrosis. A five-year follow-up study", Journal of Bone and Joint Surgery (American Volume), Vol. 76, No. 10, pp. 1464 1470,1994

[9] P. Yates, S. Serjeant, G. Rushforth, R. Middleton, "The Relative Cost of Cemented and Uncemented Total Hip Arthroplasties", The Journal of Arthroplasty, Vol. 21, No. 1, pp. 102-105, 2006

[10] S. R. Goldring, M. Jasty, M. S. Roelke, C. M. Rourke, F. R. Bringhurst, W. H. Harris, "Formation of a synovial-like membrane at the bonecement interface. Its role in bone resorption and implant loosening after total hip replacement", Arthritis \& Rheumatism, Vol. 29, No. 7, pp. 836842,1986

[11] M. Jasty, W. J. Malony, C. R. Bragdon, D. O. O'Connor, T. Haire, W. H. Harris , "The initiation of failure in cemented femoral components of hip arthroplasties", Journal of Bone and Joint Surgery (British Volume), Vol. 73-B, No. 4, pp. 551-558, 1991

[12] D. Waanders, D. Janssen, K. A. Mann, N. Verdonschot, "The behavior of the micro-mechanical cement-bone interface affects the cement failure in total hip replacement", Journal of Biomechanics, Vol. 44, No. 2, pp. 228-234, 2011

[13] L. Zouambi, B. Serier, H. Fekirini, B. Bachir Bouiadjra, "Effect of the Cavity-Cavity Interaction on the Stress Amplitude in Orthopedic Cement", Journal of Biomaterials and Nanobiotechnology, Vol. 4, No. 1, pp. $30-36,2013$

[14] ABAQUS Ver 9-11, User Guide; 2011. H.K. Sorensen. Abaqus user manual.

[15] H. F. El-Sheikh, J. B. MacDonald, M. S. J. Hashmi, "Material selection in the design of the femoral component of cemented total hip replacement", Journal of Materials Processing Technology, Vol. 122, No. 2-3, pp.309-317, 2002 
[16] G. Bergmann, F. Graichen, A. Rohlmann, "Hip joint loading during walking and running, measured in two patients, Journal of Biomechanics, Vol. 26, No. 8, pp. 969-990, 1993

[17] G. Bergmann, G. Deuretzbachir, M. Heller, F. Graichen, A. Rohlmann, J. Strauss, G. N. Duda, "Hip contact forces and gait patterns from routine activities", Journal of Biomechanics, Vol. 34, No. 7, pp. 859-
871,2001

[18] B. A. McCormack, P. J. Prendergast, "Microdamage accumulation in the cement layer of hip replacements under flexural loading", Journal of Biomechanics, Vol. 32, No. 5, pp. 467-475, 1999 